11

\title{
Плавление и электромиграция в тонких пленках хрома
}

\author{
(C) M. Sharma ${ }^{1}$, P. Kumar ${ }^{2}$, A.B. Иржак ${ }^{3}$, S. Kumar ${ }^{1}$, R. Pratap ${ }^{1}$, C.В. фоон Гратовски ${ }^{4}$, \\ В.Г. Шавров ${ }^{4}$, В.В. Коледов ${ }^{4, \uparrow}$ \\ ${ }^{1}$ Centre of Nano-Science and Engineering, \\ Indian Institute of Science (IISc) Bangalore, India \\ ${ }^{2}$ Department of Materials Engineering, \\ Indian Institute of Science (IISc) Bangalore, India \\ ${ }^{3}$ Институт проблем технологии микроэлектроники и высокочистых материалов РАН, \\ Черноголовка, Россия \\ ${ }^{4}$ Институт радиотехники и электроники им. В.А. Котельникова РАН, \\ Москва, Россия \\ ฯE-mail: victor_koledov@mail.ru \\ Поступила в Редакцию 30 декабря 2019 г. \\ В окончательной редакции 30 декабря 2019 г. \\ Принята к публикации 10 января 2020 г.
}

\begin{abstract}
Пленки хрома толщиной $10-40 \mathrm{~nm}$, нанесенные на кремниевые подложки при помощи магнетронного осаждения, были подвергнуты воздействию электрического тока, индуцированного зондом атомно-силового микроскопа $(\mathrm{ACM})$ в воздушной среде при нормальных условиях. Плавление на наноуровне, миграция материала, вызванная электрическим током и химическая реакция окисления хрома были исследованы с помощью оптической и сканирующей электронной микроскопии (СЭМ), атомной силовой микроскопии (АСМ) и спектроскопии комбинационного рассеяния света в кратерах плавления около области воздействия. Обнаружено, что течение расплавленного материала, индуцированное электрическим током, сопровождается образованием и движением массива сферических наночастиц в кратере плавления по его периферии. Предполагается, что реакция окисления хрома и поверхностное натяжение расплавленного материала на кремниевой подложке объясняют формирование массива нанокапель материала при сравнительно малых плотностях токах.
\end{abstract}

Ключевые слова: $\mathrm{Cr}$, тонкие пленки, электрический ток, АСМ, наноплавление, образование наносфер, СЭМ, спектроскопия комбинационного рассеяния света, поверхностный фазовый переход.

DOI: 10.21883/FTT.2020.06.49342.23M

\section{1. Введение}

Протекание электрического тока в твердотельном материале может вызвать химическую реакцию, особенно если реакция требует избытка электронов, что приводит к образованию химических соединений, которые не образуются в обычных условиях. Если джоулев нагрев достаточно высок, то вновь образованное химическое соединение может расплавиться и начать течение от одного электрода, где оно было образовано, в сторону другого электрода [1-3]. Эффект движения материала называется электромиграцией, он оказывается весьма существенным при высокой плотности постоянного тока $\left(>10^{4} \mathrm{~A} / \mathrm{cm}^{2}\right)$. Электромиграция связана с тем, что, если через жидкий проводник протекает электрический ток с достаточно большой плотностью, то из-за совместного действия на ионы проводника прямой электростатической силы и противоположно направлененой силы, возникающей за счет обмена импульсом между ионами и электронами (т.н. сила „электронного ветра“) жидкий металл течет по или против направления тока, в зависимости от того, какая из двух сил доминирует. Следует отметить, что доминирующая сила электромиграции должна также преодолеть потенциал связи между атомами в материале, чтобы подтолкнуть атом от его первоначального места к другому месту равновесия. В случае жидких проводящих материалов эта межатомная сила связи намного меньше чем в твердотельных [4].

Фазовые переходы в тонких пленках металлов также вызывают большой интерес в связи с потребностью обоснования температурной стабильности пленок различных твердотельных материалов на подложках в микро- и наноэлектронике. Среди них так называемые фазовые переходы смачивания представляют собой особый вид фазовых переходов, возникающих на границах раздела в условиях, когда энергия поверхностного смачивания и энергия плавления становятся близки по порядку величины [5-8]. Данный вид фазовых переходов наблюдается экспериментально для жидкостей на поверхности подложек [7-13]. Практическая значимость исследований в этой области обусловливается необходимостью прогнозирования поведения металлических покрытий, а также определения рабочего интервала температур активных и пассивных элементов микро- и наноэлектроники. В связи с этим, значительный интерес представляет изучение процессов формирования неоднородных состояний, в частности, структуры наночастиц, 


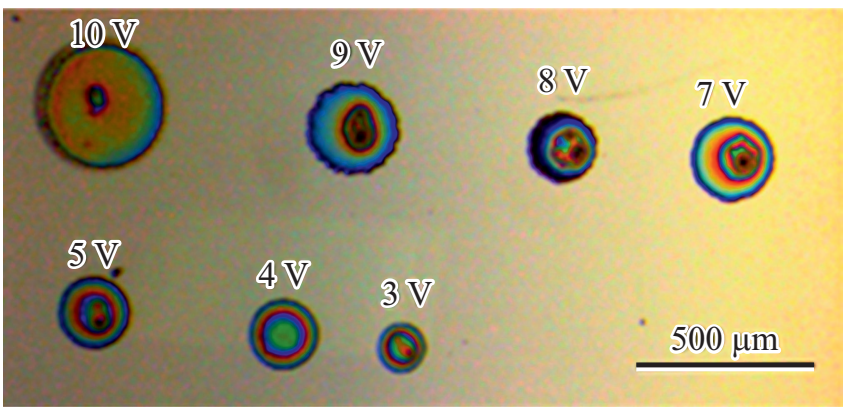

Рис. 1. Оптическая микрофотография кратеров плавления на пленках $\mathrm{Cr} / \mathrm{Si}$, образовавшихся при различных приложенных между проводящим кантилевером АСМ и поверхностью напряжениях.

в процессе фазовых переходов на наношкале размеров толщины пленок.

Настоящая работа направлена на экспериментальное изучение процессов плавления и электромиграции под действием электрического тока, вызванного приложением электрического потенциала к остроконечному зонду атомно-силового микроскопа (АСМ) в кремниевой подложке с тонкой пленкой $\mathrm{Cr}$, приводящих к формированию на периферии кратера плавления Cr структуры наноразмерных твердых металлических сфер, чего трудно достичь обычным процессом литографии.

\section{2. Образцы и методы}

Эксперименты проводились на тонких пленках $\mathrm{Cr}$, нанесенных на подложку $\mathrm{Si}$. Пластины кремния $n$-типа, в кристаллографической плоскости $\langle 100\rangle$ были предварительно очищены с использованием стандартных методов RCA 1 и RCA 2. На свежеочищенные пластины $\mathrm{Si}$ были нанесены пленки $\mathrm{Cr}$ толщиной 20, 40, 60, 80, 100, и $200 \mathrm{~nm}$ с использованием магнетронного напыления в вакууме $\sim 6 \cdot 10^{-6}$ Torr.

Эксперименты по плавлению тонких пленок $\mathrm{Cr}$ проводились с использованием АСМ с проводящим наконечником кантилевера (в режиме „С-AFM“). Электрический ток в пленке возбуждался путем подачи постоянного напряжения между проводящим наконечником АCM и наружной поверхностью пленки Cr. Напряжение изменялось в пределах от 3 до $10 \mathrm{~V}$ при сохранении постоянной времени воздействия $40 \mathrm{~s}$. Морфология полученных структур была исследована с помощью СЭМ GEMINI SEM Mono CL. Структурно-химический анализ проводили с помощью спектрометра комбинационного рассеяния света Senterra (Bruker).

\section{3. Результаты и обсуждения}

Общий вид полученных структур в форме колец или кратеров плавления показан на оптической микрофотографии на рис. 1. Видно, что диаметр колец увеличивается с ростом приложенного напряжения. На рис. 2, приведены СЭМ-изображения периферии одного из кратеров. На его краю находятся скопления частиц субмикронного размера. Они представляют собой затвердевшие капли расплавленного материала, образовавшегося в результате плавления пленки током, протекающим от центра кольца к его периферии.

Для определения состава материала в зоне плавления были получены спектры комбинационного рассе-

$a$

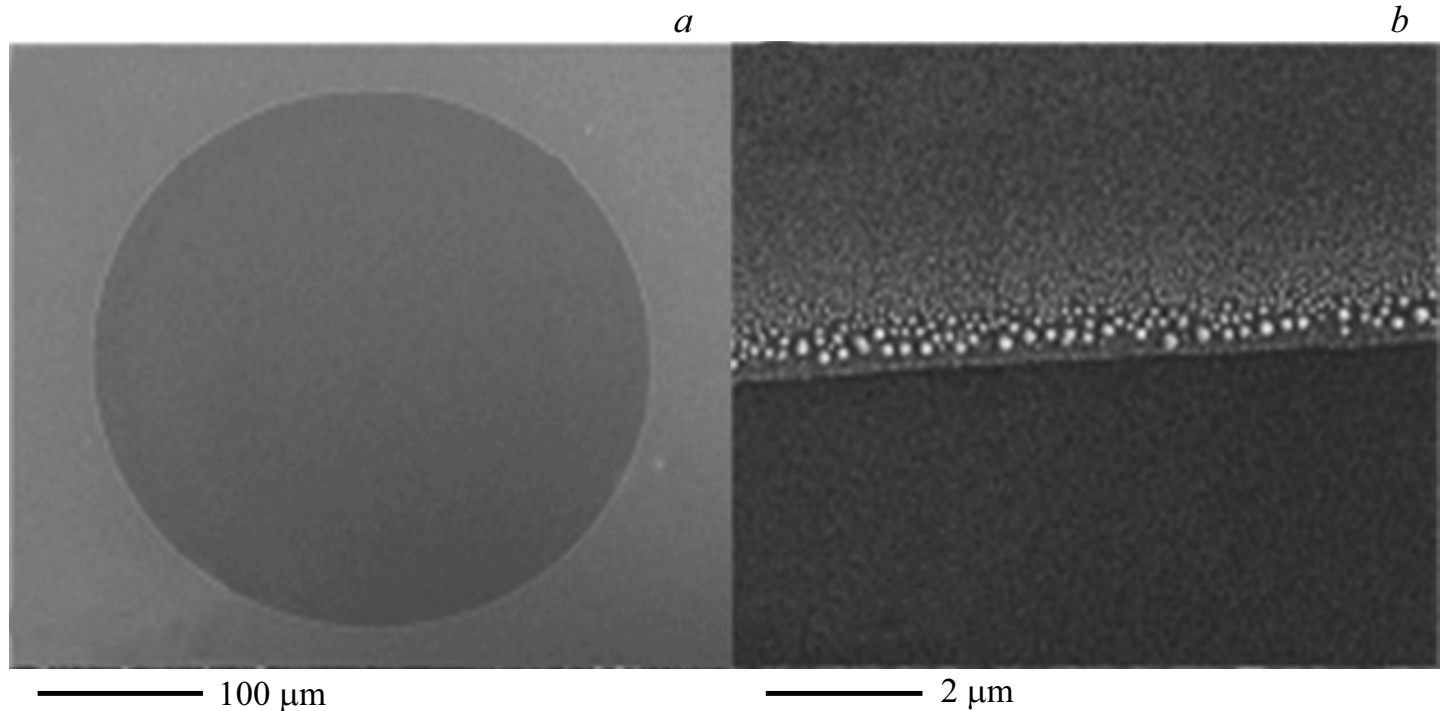

Рис. 2. СЭМ-изображение структуры субмикронных сфер, сформированных на периферии кратера плавления при подаче $10 \mathrm{~V}$ на пленку $\mathrm{Cr}$ толщиной $30 \mathrm{~nm}$, нанесенную на пластину $\mathrm{Si} . a$ - типичная кольцевая область, образованная вокруг зонда АСМ кантилевера за счет протекания электрического тока к тонкой пленке $\mathrm{Cr}$. $b$ - граница кратера плавления со сферическами частицами. 


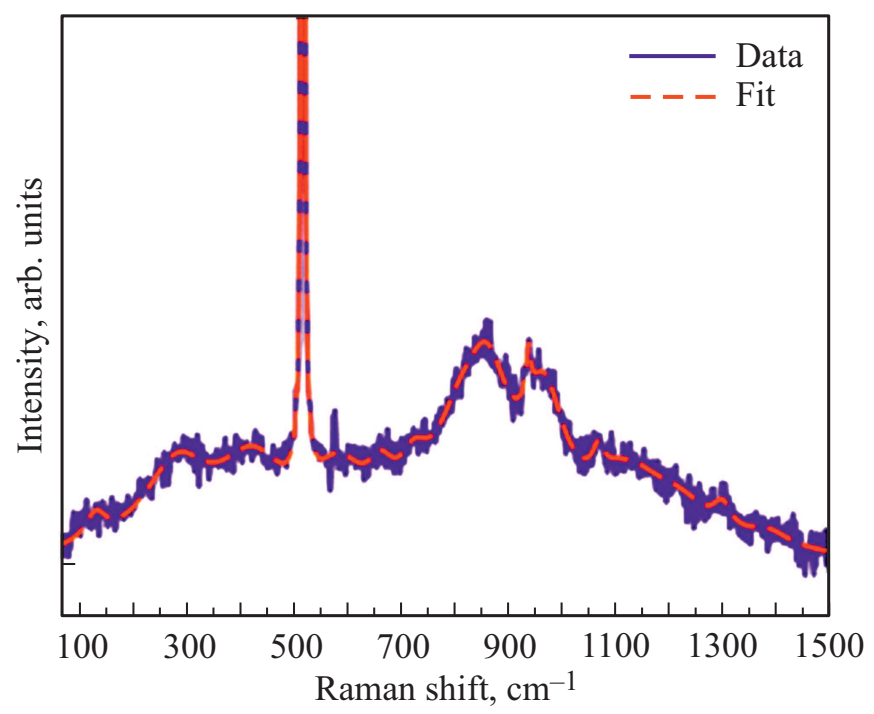

Рис. 3. Спектры комбинационного рассеяния света области пленки $\mathrm{Cr} / \mathrm{Si}$ вблизи края кратера плавления с кластерами шариков.

яния света с использованием спектрометра Senterra, Brucker. Условия получения спектров: длина волны лазера $532 \mathrm{~nm}$, мощность $0.2 \mathrm{mV}$, время накопления 10 раз по $5 \mathrm{~s}$, область спектра $50-1540 \mathrm{~cm}^{-1}$ с разрешением $3-5 \mathrm{~cm}^{-1}$. Полученные спектры представлены на рис. 3 . В спектре, помимо пиков, характерных для кремниевой подложки $\left(521 \mathrm{~cm}^{-1}\right.$ и 940-970 $\left.\mathrm{cm}^{-1}\right)$, присутствуют пики, характерные для $\mathrm{Cr}_{2} \mathrm{O}_{5}$ [14]: 838, 865, $968 \mathrm{~cm}^{-1}$.

Отметим, что ранее наблюдалась фрагментация металлических и тонких металлических пленок при фазовом переходе плавления $[15,16]$. В работе [15] пока- зано, что при нагреве кристалла до температур выше температуры Дебая происходит генерация дислокаций, а их полигонизация приводит к самопроизвольной фрагментации структуры металла. Электронная микроскопия использовалась для исследования нагрева тонких пленок чистых металлов ( $\mathrm{Fe}, \mathrm{Cu}, \mathrm{Ni}, \mathrm{Ag}, \mathrm{Au})$. Нагрев осуществлялся до температур, превышающих температуру Дебая. Наблюдалось спонтанное дробление зерен. Когда температура приближалась к температуре плавления объемного материала, явления фрагментации усливались. Когда нагрев переходит в стадию передачи скрытой теплоты плавления, он сопровождается фрагментацией кластеров с размером порядка десятков нанометров, которые сохраняются в процессе затвердевания. Начальная стадия затвердевания сопровождается увеличением количества кристаллических нанофрагментов. Также в $[16,17]$ наблюдалась фрагментация металлических тонких пленок на различных подложках в процессе плавления. В работе [16] проведено экспериментальное и теоретическое исследование размерных и температурных зависимостей поверхностной энергии; обсуждалось смачивание твердых поверхностей и свободных тонких пленок мелкими металлическими частицами. Показано, что фрагментация возникала при определенном соотношении поверхностной энергии металлической капли и энергии смачивания подложки.

Замечено, что сферические частицы формируется вблизи края области воздействия электроиндуцированного потока расплавленного материала, повторяя распределение по размерам. Сначала формируются более крупные шарики, а затем более мелкие по мере удаления от периферии кольца, как показано на рис. 4, $a, b$ (опорные точки обозначены крестиками на рис. 4, a). Размеры наносфер варьируются от $30 \pm 10 \mathrm{~nm}$ до $150 \pm 10 \mathrm{~nm}$ в

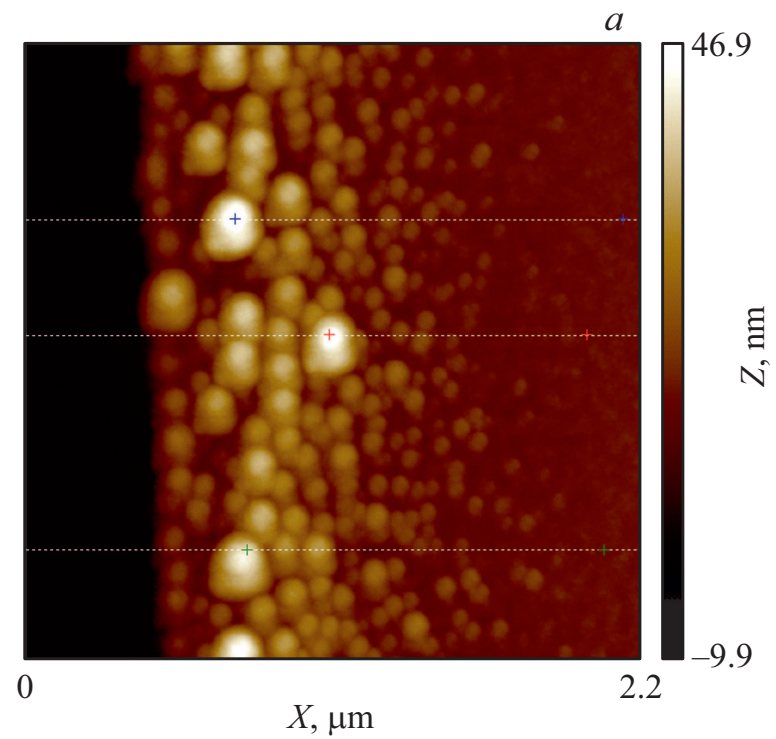

$b$

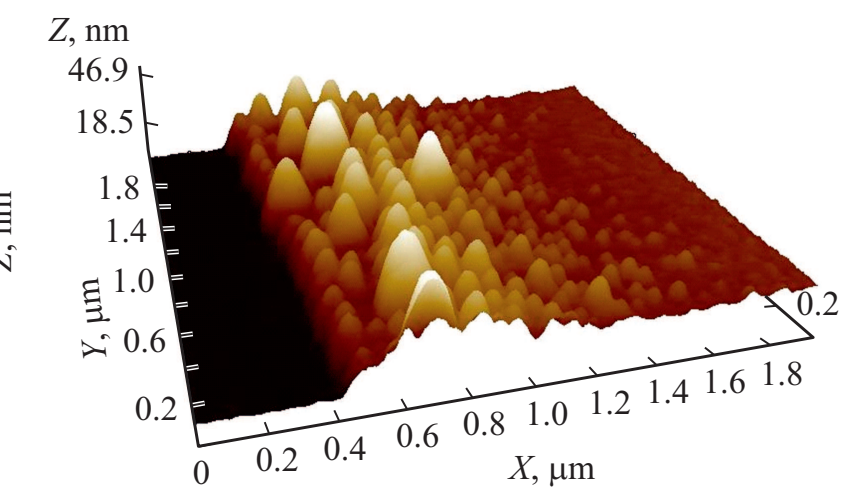

Рис. 4. АСМ-изображения, полученные при сканировании периферии одного из кратеров плавления, после образования шариков. $a$ - АСМ-изображение края области плавления. $b$ - трехмерная реконструкция структуры кластера шариков. Самые высокие шарики, опрные, отмечены крестиками. 


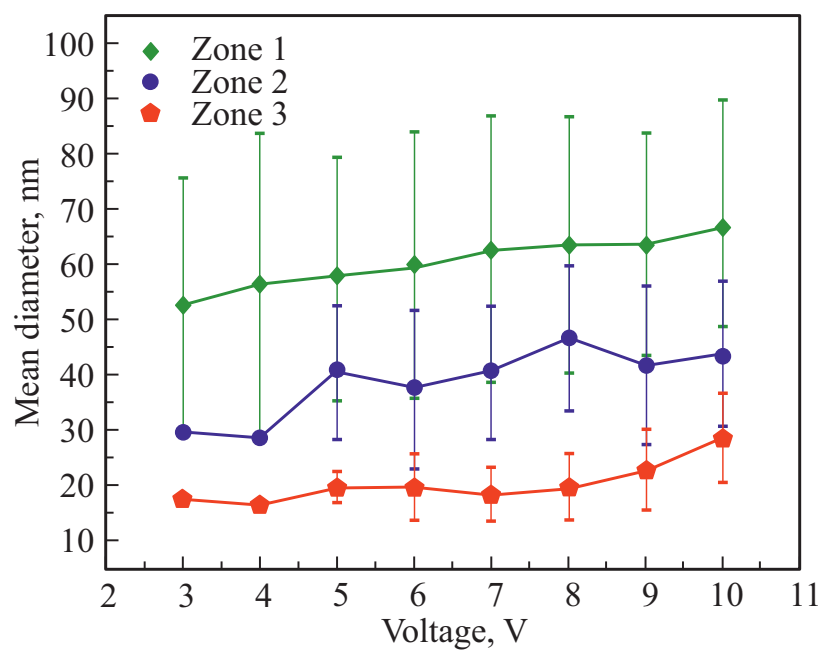

Рис. 5. Диаграмма распределения среднего диаметра сферы с дисперсией при различном напряжении в различных зонах кратера плавления.

диаметре на пленке $\mathrm{Cr}$ толщиной $20 \mathrm{~nm}$. Рспределение по размерам шариков, в зависимости от расстояния до края кратера по нормали к кольцу, указывает на то, что мелкие шарики, формируются при меньшей температуре, дальше от катода.

Для проверки повторяемости формирования матрицы наносфер были приготовлены 50 образцов кратеров при различных напряжениях в диапазоне от 3 до $10 \mathrm{~V}$ на пленке $\mathrm{Cr}$ толщиной $30 \mathrm{~nm}$. Было замечено, что образование наносфер является очень стабильным и повторяющимся эффектом и наблюдается практически во всех образцах. Таким образом, следующим шагом было проверить его зависимость от различных параметров, таких как напряжение источника и толщина пленки.

Для дальнейшей проверки статистической закономерностей формирования структуры сфер был изготовлен массив колец на пленке $\mathrm{Cr} / \mathrm{Si}$ толщиной $30 \mathrm{~nm}$ под действием напряжения изменявшегося от 3 до $10 \mathrm{~V}$, с сохранением постоянного времени воздействия - $40 \mathrm{~s}$. Было отмечено, что изменение напряжения не оказывает существенного влияния на размер шариков (см. рис. 5). Все шарики на периферии различных колец, выполненных при различном напряжении, имели размеры в одном диапазоне, но с изменением плотности шариков на единицу площади в направлении нормали к фронту плавления. По мере снижения напряжения периферия кольца становится малонаселенной. В зависимости от диаметра сфер, их массив можно разделить на три зоны. При $10 \mathrm{~V}$ большие сферы (первая зона) имеют средний диаметр $70 \mathrm{~nm}$ с дисперсией $34 \%$ от среднего диаметра, средний размер уменьшается до $\sim 40 \mathrm{~nm} \mathrm{c}$ дисперсией $30 \%$ в зоне 2, а самые маленькие сферы имеют средний диаметр $230 \mathrm{~nm}$ с дисперсией $27 \%$ в зоне 3. Таким образом, мы приходим к выводу, что по мере перемещения из зоны 1 в зону 3 дисперсия в среднем диаметре уменьшается и большее количество сфер становится одинаковым по размеру.

Эффект формирования наносфер под воздействием электрического тока преимущественно наблюдается в интервале тощин пленок $\mathrm{Cr} / \mathrm{Si}$ от 10 до $40 \mathrm{~nm}$. Размер наносфер слабо зависит от тощины пленки. Образование наносфер не происходит в вакууме или инертной среде. Это указывает на решающую роль окисления хрома, кроме толщины пленки, при формировании процессов фазового перехода и структурообразования.

\section{4. Заключение}

В результате настоящего экспериментального исследования было установлено, что путем приложения электрического тока с помощью зонда АСМ кантилевера в воздушной среде, на поверхность пленки хрома на воздухе возможно вызвать плавление хрома и химическую реакцию образования $\mathrm{Cr}_{2} \mathrm{O}_{5}$ с последующей электромиграцией полученного жидкого материала от катода к периферии расплавленных колец. На периферии кратера плавления происходит формирование матрицы сферических наночастиц, которые переносятся электрическим током к его краю. Спектроскопия комбинационного рассеяния света подтверждает, что в окрестности периферии кратеров плавления вокруг наконечника зонда АСМ присутствуют частицы оксидной фазы $\mathrm{Cr}_{2} \mathrm{O}_{5}$. Эти наблюдения согласуются с [18], где показано, что нагревание оксидов хрома в воздухе вызывает последовательность фазовых переходов и химических реакций, причем температура плавления сильно снижается за счет последовательного поглощения материалом кислорода. Как было показано ранее в [19], при плавлении вакуумно осажденных пленок Sn и Вi на углеродной подложке, если расплав не смачивает подложку, то пленка перед плавлением разделяется на островки, что приводит к образованию частиц узкого диапазона размеров после плавления. Температура сегрегации начинает понижаться по мере уменьшения толщины пленки. Таким образом, изученное в работе влияние электрического тока, индуцирующего плавление тонкой пленки $\mathrm{Cr}$, и сопровождающееся образованием и миграцией шариков, может быть связано со снижением температуры в нанослоях $\mathrm{Cr}$, а также с химическим окислением расплава $\mathrm{Cr}$ и физической сегрегацией жидкой фазы на несмачиваемой поверхности подложки. Эффект формирования металических сферических наночастиц может найти применение при создании технологии наносборки „снизу вверх“ для нового поколения наноэлектроники и наносенсорики [20].

\section{Финансирование работы}

Работа в части исследования фазового перехода на наношкале выполнена при финансовой поддержке Российского научного фонда (проект № 17-19-01748), в 
части исследования электромиграции работа частично поддержана гратами департамента науки и технологий Правительства Индии (DSTO 1759) и РФФИ (проект № 17-57-45129).

\section{Конфликт интересов}

Авторы заявляют, что у них нет конфликта интересов.

\section{Список литературы}

[1] S. Talukder, P. Kumar, R. Pratap. IEEE Transact. Electron Dev. 60, 9, 2877 (2013).

[2] S. Talukder, P. Kumar, R. Pratap. Science 108, 2167 (2015).

[3] S. Kumar, P. Kumar, R. Pratap. J. Phys. D 50, 39LT02 (2017).

[4] S. Krumbein. Metallic Electromigration Phenomena. In Electromigration and Electronic Device Degradation / Ed. A. Christou. John Wiley \& Sons (1994).

[5] Nanoscale liquid interfaces / Ed. T. Ondar, J.P. Aiḿ e. CRC Press Taylor\&Francis Group, Boca Raton (2013). 769 p.

[6] J. Cahn. J. Chem. Phys. 66, 3667 (1977).

[7] D. Bonn, J. Eggers, J. Indekeu, J. Meunier, E. Rolley. Rev. Mod. Phys. 81, 739 (2009).

[8] A. Oron, S.H. Davis, S.G. Bankoff. Rev. Mod. Phys. 69, 931 (1997).

[9] П.Е. Львов, В.В. Светухин, С.В. Булярский, А.А. Павлов. ФTT 61, 10, 1916 (2019).

[10] J. Becker, G. Gr?un, R. Seemann, H. Mantz, Kh. Jacobs, K.R. Mecke, R. Blossey. Nature Mater. 2, 59 (2003).

[11] R.V. Craster, O.K. Matar. Rev. Mod. Phys. 81, 1131 (2009).

[12] X.-J. Cai, J. Genzer, R.J. Spontak. Langmuir. 30, 11689 (2014).

[13] M. Kalloudis, E. Glynos, S. Pispas, J. Walker, V. Koutsos. Langmuir. 29, 2339 (2013).

[14] J.E. Maslar, W.S. Hurst, T.A. Vanderah, I. Levin. J. Raman Spectrosc. 32, 201 (2001).

[15] В.П. Майборода, А.П. Шпак, Ю.А. Куницкий. Успехи физики металлов 4, 3, 123 (2003).

[16] М.М. Колендовский, С.И. Богатыренко, А.П. Крышталь, Н.Т. Гладких. ЖТФ 82, 6, 115 (2012).

[17] S.V. Dukarov, O.P. Kryshal, V.N. Sukhov. Surface Energy and Wetting in Island Films. Wetting and Wettability, (2015). P. 169-206.

[18] S. Labus, A. Malecki, R.Gajerski, Journal of thermal analysis and calorimetry. 74, 1, 13 (2003).

[19] С.В. Дукаров, В.Н. Сухов, И.Г. Чурилов. Вестн. ХНУ, 865. Сер. физ. 12, 77 (2009).

[20] S. von Gratowski, V. Koledov, V. Shavrov, S. Petrenko, A. Irzhak, A. Shelyakov, R. Jede. Advanced System for Nanofabrication and Nanomanipulation Based on Shape Memory Alloy. In Frontiers in Materials Processing, Applications, Research and Technology. Springer, Singapore (2018). P. $135-154$.

Редактор К.В. Емцев 